\title{
¿UN SISTEMA DE GOBIERNO SEMIPRESIDENCIAL? Notas escépticas sobre una posible reforma institucional
}

\author{
MANUEL MARTIINEZ SOSPEDRA \\ P. ordinario de Derecho Constitucional \\ CUEJ-CEU.UV-EG
}




\section{SUMARIO}

1. INTROdUCCIÓN. 2. La hUIDA del BLOQUeO COMO VÍA DE SALIDA DEL PRESIDENCIALIS-

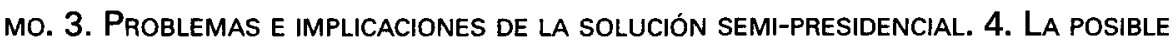
VIA PARLAMENTARIA. 5. ¿EL PARLAMENTARISMO DE ELECCIÓN DIRECTA? 


\title{
¿UN SISTEMA DE GOBIERNO SEMIPRESIDENCIAL?** Notas escépticas sobre una posible reforma institucional
}

POR

\author{
MANUEL MARTÍNEZ SOSPEDRA \\ P. ordinario de Derecho Constitucional \\ CUEJ-CEU.UV-EG
}

\section{INTRODUCCIÓN}

El debate sobre la reforma del texto constitucional chileno heredado del régimen militar no se ha limitado a la parte dogmática de la Constitución, sino que ha entrado de lleno en lo que, a mi juicio, constituye el núcleo esencial de cualquier Constitución: el sistema de gobierno, ya que de las tres preguntas clásicas quién, cómo y para qué manda, las dos últimas son necesariamente variables de la primera. Quien manda es el problema lógica y sistemáticamente primario, no en vano las reglas que lo determinan vienen a absorber prácticamente el texto constitucional en la concepción kelseniana'. La puesta en cuestión se ha venido a plantear en términos que, por su radicalidad, no tienen paralelo en el constitucionalismo de América Latina, porque, a diferencia de lo que es común, el debate no discurre bajo la égida del sistema de gobierno presidencial $y$, en consecuencia, no se limita a

* Comunicación para la XXVIII Jornada Chilena de Derecho Público. Concepción. Noviembre de 1997.

1 En la que, conviene recordarlo, las normas de lo que Posada denominaba la "parte dogmática" son meros mandatos dirigidos al Legisladores. 
proponer la introducción de nuevas instituciones (de las que un sistema de justicia constitucional concentrada es la más popular) o a reformar en mayor o menor medida el esquema presidencial heredado mediante la introducción de figuras nacidas en el seno de otros sistemas de gobierno (la configuración de Ejecutivo como órgano al menos parcialmente colegiado y la subsiguiente creación del órgano constitucional "Consejo de Ministros" y, ocasionalmente, incluso la figura del Primer Ministro), antes bien, afecta al diseño del sistema de gobierno mismo.

La puesta en cuestión del modelo presidencial es aún más relevante en el caso chileno por dos razones adicionales de no escasa importancia: Chile cuenta con una larga tradición de gobierno constitucional efectivo, mucho más amplia y profunda no sólo que la de la mayor parte de los países de su entorno, sino más prolongada y arraigada que en la mayoría de los países europeos. No se trata, pues, de un debate en torno a un gobierno constitucional efectivo de nueva o al menos reciente creación, que carente de una tradición propia puede gozar de la capacidad de maniobra que brinda un pasado inasumible y rechazado; más bien al contrario, Chile tiene la tradición señalada y la misma tiene tal peso que consideraciones propias de esa tradición desempeñaron un papel nada desdeñable en las crisis políticas que han conducido a una ruptura, siempre transitoria, del orden constitucional. De otro lado, y si exceptuamos el período de la "república parlamentarian, ceñida en lo esencial a los primeros años del siglo que muere ${ }^{2}$, la vida institucional de la República ha transcurrido bajo dos textos (1833, 1925) marcadamente presidencialistas. Por ello se puede afirmar que la tradición chilena de gobierno constitucional efectivo es una tradición predominantemente presidencialista. Cabe preguntarse el porqué de la radicalidad de un debate cuyos términos vienen a poner en cuestión una parte nada desdeñable de la tradición política de la República.

\section{LA HUIDA DEL BLOQUEO COMO VÍA DE SALIDA DEL PRESIDENCIALISMO}

Si mi percepción de los términos del debate es correcta la puesta en cuestión del modelo presidencial no puede ser desligado de los

2 No voy a entrar en la cuestión de la corrección técnica de tal expresión, que me parece más bien escasa. Por si sólo el mero desplazamiento del eje del sistema de la presidencia a las Cámaras no permite la definición del sistema como parlamentario. 
sucesos que configuraron la crisis constitucional de 1973, preámbulo, a mi juicio necesario, de la ruptura violenta del orden constitucional. No me parece el momento ni el lugar, ni desde luego el que suscribe es la persona adecuada, para describir "Los defectos de la Constitución de 1925", pero, a los ojos de un observador externo, un sistema que permite la aparición de un presidente minoritario en el voto popular $y$ que debe el cargo a la votación parlamentaria, que debe coexistir con mayorias parlamentarias hostiles y debe gobernar con unas reglas que exigen imperativamente el acuerdo de al menos una de las Cámaras parlamentarias para disponer de algunos instrumentos necesarios de gobierno, que tiene que desarrollar un ambicioso programa legislativo y no cuenta con el apoyo parlamentario indispensable para ello, en el que el Presidente puede ser el líder de la mayor fuerza política del país, pero ello no le asegura la dirección de la mayoria parlamentaria, y en el que un conflicto persistente entre el Ejecutivo y el Legislativo carece de solución constitucional es especialmente vulnerable en caso de polarización política acentuada ${ }^{3}$.

La reflexión actual sobre el sistema institucional está marcada, pues, por la voluntad de minimizar, y en el extremo suprimir, las posibilidades de bloqueo institucional, dado que los costes de ese bloqueo pueden ser enormes. Para ello se puede explorar en tres direcciones: la adaptación del sistema presidencial, la adopción de un sistema semipresidencial y la opción por un auténtico sistema de gobierno parlamentario.

Obviamente la vía de solución más fácil sería, a no dudarlo, la primera. $Y$ ello al menos por cuatro razones distintas: mayor conformidad con la tradición constitucional chilena, mantenimiento del cuadro general al que los ciudadanos están habituados, menor distancia y mayor proximidad respecto del ordenamiento vigente y por ende menor dificultad de la reforma. En pocas palabras, los hábitos, la cultura politica, el grado de dificultad, son menores $y$, por consiguiente, resulta razonable presumir que los costes de transacción serían más bajos y el indispensable acuerdo constitucional más sencillo de alcanzar.

3 Hay que advertir que en el paradigma USA el escenario de conflicto grave $y$ persistente es improbable en esencia por tres razones: la simultaneidad de la elección presidencial y la de la mayor parte del Congreso, la brevedad del mandato de la Cámara de Representantes y la labilidad de los partidos políticos en el escalón federal. Pero difícil no es imposible, cabe recordar el conflicto entre A. Johnson y la mayoría radical del Congreso en los años posteriores de 1865. 
Naturalmente las reformas a introducir no tendrían la trascendencia que es inherente a las otras vías, precisamente por eso el acuerdo es, en principio, más sencillo de alcanzar, pero de ello no se sigue fueran de poca importancia. A la vista de la experiencia me parece que, sobre el modelo "1925" seis serían los cambios a introducir: en primer lugar se deberia huir de la posibilidad del presidente minoritario, una elección directa mediante escrutinio mayoritario a dos vueltas con desempate me parece la fórmula idónea ${ }^{4}$; en segundo lugar debería haber coincidencia entre elección parlamentaria y elección presidencial ${ }^{5}$, lo que comporta en tercer lugar que el período de mandato del Congreso y del Presidente debe ser idéntico y plantea inevitablemente un difícil problema en el caso de vacancia de la Presidencia ya que la solución idónea para procurar el mantenimiento de la coincidencia electoral es la disolución ope legis del Parlamento ${ }^{6}$, y no parece que un Parlamento susceptible de disolución sea muy coherente con el modelo presidencial; en cuarto lugar obligaría a un sistema de elección del Parlamento mayoritario o al menos mixto, pues de otro modo no resulta fácil obtener que la coincidencia electoral produzca concordancia entre la mayoría presidencial y la parlamentaria7; en quinto lugar vendría a exigir la desaparición de las normas que limitan la iniciativa parlamentaria salvo tal vez en materia presupuesta-

4 El sistema de 1925 no es satisfactorio por dos razones: no impide el problema del presidente minoritario y sitúa al Parlamento ante la tesitura de o bien provocar una mutación del sistema de gobierno eligiendo discrecionalmente al Presidente, con lo que la puerta a la transformación parlamentaria queda abierta, o bien adoptar el uso de elegir al más votado, en cuyo caso su intervención es superflua. Claro que la elección por mayoría simple al estilo venezolano es aún peor: prácticamente garantiza que sólo habrán Presidentes minoritarios. Convendria, pues, conservar el sistema previsto por el art. 26 de la Constitución de 1980, aunque ciertamente el mandato presidencial debería acortarse, los ocho años del párrafo segundo del art. 25 comenzarían a exceder de lo razonable en el caso del Presidente de una república parlamentaria o semipresidencial y resultan disfuncionales en un sistema presidencial. Democrático, claro.

5 Lo que obliga al unicameralismo o a un bicameralismo en el que el mandato de ambas Cámaras es coincidente, lo que no parece una solución muy brillante precisamente.

${ }_{6} \quad$ La única alternativa razonable es un Vicepresidente elegido del mismo modo $y$ en el mismo ticket que el Presidente.

7 En contra de la tradición electoral chilena, marcadamente proporcionalista. No obstante el problema se podría resolver, o al menos paliar, con un sistema electoral que favoreciera, en el extremo forzara, las coaliciones electorales, un poco al estilo del sistema alemán. 
ria; finalmente exigiría la adopción de alguna clase de mecanismo de legislación de urgencia ${ }^{8}$.

No obstante el problema fundamental que esta opción plantea no recibiría solución a través de medidas del tipo de las señaladas. La cuestión medular que se plantea podría formularse del siguiente modo: el sistema de gobierno presidencial busca limitar el poder mediante su división radical, mediante la asignación de esferas de competencia exclusivas a las distintas ramas del Gobierno, tal esquema tiene sentido si, y sólo si, los actores políticos que controlan cada una de las ramas del Gobierno son ordinariamente distintos de tal modo que un sólo actor político no pueda controlar simultánea y sólidamente dos o más de dos. En presencia de partidos centralizados, dotados de una fuerte organización nacional, de reclutamiento preciso y masivo y capaces de exigir y obtener disciplina de sus fracciones parlamentarias, como es la norma en Europa y es el caso chileno, el mantenimiento de los supuestos implícitos del sistema presidencial exige la no coincidencia de mayorías. El riesgo de bloqueo persistente es el precio a pagar, porque el problema de fondo es que el presidencialismo se aviene poco y mal, o no se aviene en absoluto, con partidos al estilo europeo. En otras palabras, la combinación entre sistema de gobierno presidencial, partidos fuertes y reglas que procuran la coincidencia de mayoría comporta una fuerte apuesta en favor de un gobierno sin limitaciones eficaces del poder, un sistema en el que el poder se concentra en un Presidente de elección directa que, al tiempo y por serlo, es el líder de la mayoría parlamentaria9.

En consecuencia, insisto, el riesgo del bloqueo es un coste inherente a la opción en favor del sistema presidencial. Por tanto, si se desea evitar ese peligro sin necesidad de caer en el alternativo de una concentración excesiva del poder hay que abandonar la opción presidencialista. La lógica del presidencialismo excluye tanto la colaboración por integración como la coordinación por vía partidaria, de ahí que el rechazo al riesgo de bloqueo institucional, cuando pasa

8 En todo caso me parece que sería indispensable el mantenimiento de un sistema de justicia constitucional, si bien me parece que éste debería configurarse preferentemente como un control represivo, y no preventivo como el actual, $y$ mediante la adopción de un sistema de justicia constitucional concentrada, que me parece preferible al sistema de control difuso entre otras razones porque en éste, a diferencia de aquel, no hay control alguno sobre el Poder Judicial, $y$, como señala Manzella, un juez faccioso puede estar en el horóscopo de cualquiera.

9 Y que controlando la rama legislativa y la rama ejecutiva del Gobierno tiene el camino expedito para controlar el Poder Judicial. 
a primer plano, venga a operar como una vía de salida del presidencialismo.

\section{PROBLEMAS E IMPLICACIONES DE LA SOLUCIÓN SEMI-PRESIDENCIAL}

Un sector de la doctrina chilena ha venido a postular como vía de solución la adopción de un sistema de gobierno semi-presidencial. Las razones subyacentes a esa opción son al tiempo claras y fuertes, en esencial tales argumentos pueden ser reducidos a dos fundamentales: en primer lugar no existe riesgo de bloqueo en caso de conflicto entre el Gobierno y el Parlamento, ya que el mismo puede ser levantado en caso necesario mediante el juego de los principios de confianza y responsabilidad, de un lado, y mediante el recurso al arbitraje de cuerpo electoral mediante la disolución y convocatoria de nuevas elecciones, del otro. De este modo el Parlamento puede forzar la dimisión del Gobierno, a cambio éste puede situar a los parlamentarios ante la alternativa de apoyar medidas propuestas por el Ejecutivo o arriesgar el escaño en una eventual consulta electoral. Es improbable el posible bloqueo del Ejecutivo por el obstruccionismo parlamentario, dada la facultad de disolución, es improbable, asimismo la adopción de decisiones parlamentarias capitales contra el criterio gubernamental. En todo caso si el riesgo se materializase el sistema proporciona salidas: el Gobierno puede plantear la cuestión de confianza y colocar a los parlamentarios ante la responsabilidad de producir la caída del gobierno, al tiempo que deja expedito el camino de la disolución, la Cámara puede derribar a un gobierno minoritario mediante una moción de censura, finalmente el Presidente puede arbitrar el contencioso y tiene la autoridad política y las facultades necesarias para ello.

En segundo lugar el modelo semi-presidencial es compatible con la tradición constitucional chilena al mantener el uso de la elección directa del Jefe del Estado y su condición de rector del Ejecutivo y director de la política nacional. A diferencia de la opción parlamentaria, ligada a recuerdos poco gratos para amplios sectores de opinión, y que en buena medida supone una construcción extraña a la tradición chilena, la opción semi-presidencial parece reunir las ventajas de la adecuación al tiempo y al lugar junto con la combinación de los elementos positivos del modelo parlamentario y el presidencial sin caer en riesgo de bloqueo alguno. Adicionalmente puede alegarse en su favor un tercer argumento, bien que de tono menor: el no escaso uso y la amplia experiencia existente en su viabilidad y éxito en sistemas de partidos 
sustancialmente similares al chileno, como son los europeos e incluso su adopción por un Estado-paradigma: la República francesa.

En sustancia la opción semi-presidencial predica una reforma institucional basada en cuatro puntos esenciales: primero, el mantenimiento de la elección directa del Presidente ${ }^{10}$, configurado como cabeza del Ejecutivo; segundo, la asignación al Jefe del Estado de facultades propias que ejerce por sí mismo, junto a otras que ejerce con acuerdo y mediante el Consejo de Ministros ${ }^{11}$; tercero la necesidad de que el Gobierno, cuyo nombramiento toca al Presidente por sí o a propuesta del Primer Ministro, cuente necesariamente con la confianza del Parlamento ${ }^{12}$, de tal modo que el Gobierno queda facultado para plantear la cuestión de confianza ante la Cámara y a su vez, ésta puede provocar la caída del gobierno mediante la adopción de una moción de censura; cuarto, el Presidente de la República cuenta con la facultad de disolver anticipadamente el Parlamento ${ }^{13}$.

10 En los países de la Unión Europea que comparten el modelo la elección es siempre directa tras la abolición del colegio de compromisarios existente hasta 1992 en Finlandia.

11 No voy a entrar en la técnica a usar tanto para fijar la esfera de competencia propia del Presidente como para establecer la esfera de competencia del Gobierno, ni en el catálogo de facultades reservadas al Presidente. En todo caso debe hacerse notar que en los países europeos que siguen el sistema (Finlandia, Austria, Francia y Portugal) las técnicas de reparto difieren y también lo hace la definición de los poderes presidenciales. No se han tenido en cuenta, por lo reciente de la experiencia, los supuestos de Polonia y Rumania.

12 En los dos casos en los que el Parlamento es bicameral (Francia y Austria) sólo de la Cámara Baja del Parlamento (Asamblea Nacional y Consejo Nacional, respectivamente). En los cuatro casos el Presidente designa a los Ministros a propuesta del Primer Ministro.

13 Cuestión distinta es la del Senado. Por de pronto el Senado del art. 45 de la Constitución vigente me parece inservible no porque haya senadores vitalicios, que los hay en Senados democráticos como el italiano, $y$ no me parece que el hacer Senadores a los ex-presidentes sea necesariamente una mala idea más allá de la simpatía que nos pueda merecer cada uno de los titulares, ni porque el sistema previsto para la elección de la parte electiva del Senado sea digno de figurar en los anales de la picaresca electoral, a la postre esos inconvenientes se pueden resolver de modo muy simple suprimiendo el inciso final del primer párrafo del art. 45 citado. Me parece inservible por su concepción: el Senado de la República esta concebido como el órgano de representación de una élite, de la maior ac melior pars reipublicae, cuerpo en el que late la idea jovellanista de que la nobleza carece de estatuto político si no tiene una Cámara propia. Es, pues, pieza que tiene sentido en un "gobierno mixto", del cual es elemento esencial, pero deviene un cuerpo extraño en un ordenamiento democrático. En todo caso si la reforma conservara el Senado y lo incorporara a un modelo semi-presidencial, la Cámara Alta debería ser de renovación 
Ahora bien, ese conjunto de reformas suponen en pocas palabras la combinación entre un parlamentarismo de doble confianza y un Jefe del Estado de elección popular directa. No suponen un mero retorno a lo que la doctrina francesa suele denominar "orleanismo" porque el Jefe del Estado no es un monarca o un magistrado electo por los parlamentarios y/o con su intervención, antes bien, suponen un fenómeno nuevo por cuanto el sistema institucional combina la existencia de dos representantes del pueblo con investidura directa (Cámara y Presidente) con la necesidad de doble confianza que, a su vez, implica la atribución al Jefe del Estado de facultades propias de tal modo que su concurso es indispensable para gobernar ${ }^{14}$.

Ahora bien, en un sistema semi-presidencial precisamente porque el mismo pivota sobre la existencia de dos representantes inmediatos y directos del soberano constitucional, aparece un problema peculiar, cual es el de la relación Presidente/Parlamento. Es de notar que el problema no aparece por la asignación al Jefe del Estado de facultades de gobierno, a diferencia de la que sucede con el decimonónico sistema parlamentario de doble confianza, sino que deriva de la elección directa, ya que un diferendo entre la Presidencia y la Cámara aparece necesariamente no como un conflicto entre el representante directo $y$ el mediato del soberano constitucional ${ }^{15}$, sino como un conflicto entre representantes directos del pueblo.

El riesgo del conflicto señalado es inherente a la combinación entre parlamentarismo de doble confianza y elección presidencial directa. $Y$, al igual que sucede que en el sistema de gobierno presidencial, carece de solución constitucional. Es cierto que, a diferencia de los que sucede en aquél, el bloqueo no aparece de forma directa e inmediata, en este sentido el sistema semi-presidencial es más flexible y permite no sólo un eventual arbitraje de los electores sino mayores

parcial periódica (me parece adecuada la previsión del segundo párrafo del art. 45), $y$, en consecuencia, no susceptible de manifestar el principio mayoritario ni ser de disolución.

14 En otras palabras, no basta la elección directa del Presidente, además es necesario que el Jefe del Estado tenga facultades de intervención en el gobierno cuotidiano de la República y por ello su asentamiento sea indispensable para gobernar. En caso de que tales facultades no existan no habrá ni semi-presidencialismo ni doble confianza, como muestran los casos islandés e irlandés. Del mismo modo tampoco lo hay si el Presidente no es de elección popular, como en Grecia hoy o en el régimen previsto en la Constitución española de 1931, aun cuando el Presidente tenga poderes propios.

15 Que define el escenario de la crisis francesa del «seize de mai». 
márgenes de tiempo y suministra un escenario más favorable a la negociación. Pero no es menos cierto que si el Presidente y la mayoría parlamentaria se encastillan en sus posiciones $y$ ambos reciben el suficiente apoyo electoral en caso de recurso a las urnas no hay salida. O no la hay salvo en el caso heterodoxo de que el Presidente decida salvar el bloqueo dimitiendo por sentirse desautorizado por el electorado que no avala una decisión propia o reproduce la mayoria parlamentaria ${ }^{16}$.

En todo caso el problema más importante que la solución semipresidencial plantea no es ninguno de los citados, sino otro bien distinto y que se halla no tanto en la configuración de las instituciones cuanto en el juego entre las fuerzas políticas. Por de pronto hay que advertir que el sistema funcionará de forma totalmente distinta según haya o no una mayoría monocolor en el Parlamento, o, alternativamente, una coalición mayoritaria sólida y estable en la Cámara. Si ello sucede, esto es, si en el Parlamento existe un partido o coalición estable y coherente que alcanza la mayoría absoluta la consecuencia que se sigue es la reducción drástica del papel político del Presidente, que incluso puede quedar reducido de facto al papel cuasisimbólico del Presidente débil propio de una oganización parlamentaria ${ }^{17}$. Si ese escenario se produce no hay en rigor sistema semipresidencial pues el Ejecutivo es absorbido por un Gobierno respaldado por la mayoría en el Parlamento ${ }^{18}$.

El modelo no sólo se puede desvirtuar mediante la minimización del Jefe del Estado, también puede serlo en sentido inverso. Si existe una mayoría parlamentaria como la arriba descrita y el Presidente es su líder el resultado necesario es la reducción del papel del Gobierno y del Primer Ministro a una posición ancilar y la concentración del poder en manos del Presidente. Es la situación considerada "normal» en Francia:

16 Es el caso de la dimisión del general De Gaulle en marzo de 1969.

17 El ejemplo de rigor es el caso de Austria: a pesar de que la Constitución Federal otorga al Presidente poderes propios mayores que los que le atribuye la Constitución francesa, al respecto baste comparar el art. 19 del texto francés con los arts. 65 y ss. del austríaco, la existencia constante de una mayoría parlamentaria sólida y disciplinada ha conducido al paso a segundo término del Presidente y a la hegemonía del Canciller. Pero no es el único, como muestra el caso portugués.

18 Por eso no me parece precisamente casual que no se haya dado en la realidad la combinación entre la elección directa de un Presidente y un sistema electoral de mayoria relativa. Antes bien, la combinación siempre se produce con un Parlamento electo mediante estrutinio proporcional 0 , al menos, por un método de escrutinio que favorece el multipartidismo, aunque sea moderado por la práctica coalicional (caso único de Francia). 
el Presidente suma a sus propias facultades el control del Legislativo que le proporciona la mayoría parlamentaria y la correspondiente al Gobierno, destinado a ser un órgano servicial al estar situado y necesitar de dos confianzas que resultan ser una sola: la del Presidente. En razón de ello ninguna Constitución semipresidencial permite la coincidencia de elecciones, parlamentaria y presidencial, generalmente mediante el expediente de atribuir al Presidente un mandato de mayor duración que el parlamentario.

Finalmente el modelo es vulnerable a bruscas oscilaciones según haya o no coincidencia entre mayoria parlamentaria y presidencial: si hay coincidencia todo el poder es asumido por el Presidente, sobre cuya acción no existen controles efectivos ${ }^{19}$, si no hay coincidencia se pasa sin transición de la cuasiomnipotencia del Presidencia a la reducción del mismo al papel de poder moderador (que es la situación actual bajo la "cohabitación" en Francia).

El modelo puede no obstante resultar estable, pero las condiciones de estabilidad dependen en esencia de factores extrainstitucionales de los cuales el fundamental es el sistema de partidos. El más destacado ejemplo es el finés: el texto constitucional de $1919^{20}$ establecía un sistema semipresidencial que divide el Ejecutivo entre el Gobierno y el Presidente. El modelo semi-presidencial se manifiesta con singular pureza: el Presidente es elegido por el pueblo y goza de poderes propios que se manifiestan en la determinación de un área (relaciones exteriores, defensa, relaciones institucionales principalmente) en la que su posición es dominante, lo que se traduce en el poder presidencial de prescribir políticas y decisiones a los ministros competentes en dichos asuntos, en los demás asuntos el Presidente tiene las atribuciones propias de un Jefe de Estado parlamentario. Además el Presidente designa al premier $y$, a su propuesta, a los demás miembros del Gobierno, en tanto que el gabinete es responsable ante la Eduskunta ${ }^{21}$, ante la

19 Salvo que exista una justicia constitucional eficiente. En cuyo caso es la Corte Constitucional el único obstáculo institucional que separa al Presidente de un poder cuasiabsoluto.

20 En rigor la Ley fundamental sobre la forma de Gobierno, ya que Finlandia sigue el sistema sueco de una Constitución fragmentada en varias leyes fundamentales.

21 El Parlamento finés es unicameral, y ello pese al plurilingüismo oficial de base étnica (lapones y minoría sueca) y pese a la existencia de regiones autónomas (islas Aland). Una de las cuestiones a plantear en caso de reforma de la Constitución vigente en sentido semi-presidencial sería precisamente la del bicameralismo, difícil de justificar satisfactoriamente en un Estado democrático de forma rigurosa- 
cual está obligado a presentar de forma inmediata su programa, de tal modo que el gobierno cae en el caso de retirada de la confianza de la Cámara, que puede ser disuelta por el Presidente. El sistema reposa sobre un Parlamento unicameral electo mediante escrutinio proporcional en el marco de un sistema de partidos fuertemente fragmentado ${ }^{22}$, $y$ en el que las costumbres han propiciado un alto grado de despartidización de la elección presidencial, que llega incluso al punto de celebrar elecciones a la Presidencia con un candidato único apoyado por casi todos los partidos ${ }^{23}$.

Ciertamente el paisaje político chileno parece responder a los presupuestos políticos que han hecho estable el modelo semipresidencial en el caso finés, que es poco menos que un caso único, dado que la tradición electoral chilena es proporcionalista y Chile no ha conocido la situación de un partido en condiciones de ser por sí mismo mayoritario o cuasimayoritario desde la definición del presente sistema de partidos, y aun bastante antes. No obstante me parece que hay factores que permiten dudar de ese juicio, piénsese que no sería muy disímil el que emitiríamos si nos situáramos en Francia en el otoño de 1958.

Aun aceptando que en el caso de Chile concurren una tradición electoral favorable y un sistema de partidos que hace improbable la aparición de mayorías estables y coherentes en el Parlamento, me parece que la eventual reforma constitucional al efecto de introducir un

mente unitaria, y de fundamentos débiles fuera del caso de la representación territorial.

22 Los resultados de las dos últimas elecciones son los siguientes:

\begin{tabular}{lcccc}
\hline Finlandia & \multicolumn{2}{c}{1995} & \multicolumn{2}{c}{1991} \\
\cline { 2 - 5 } Partidos & $\%$ WVE & Esc. & $\%$ VVE & Esc. \\
\hline SDP & 28,3 & 63 & 22,1 & 48 \\
KESK & 19,9 & 44 & 24,8 & 55 \\
KOK & 17,9 & 39 & 19,3 & 40 \\
VL & 11,2 & 22 & 10,1 & 19 \\
SFP & 5,1 & 12 & 5,5 & 12 \\
Verdes & 3,0 & 7 & 3,01 & 8 \\
SMP & 1,3 & 1 & 4,8 & 7 \\
\hline
\end{tabular}

23 La práctica se remonta a la década de 1940 y se consolidó esencialmente en torno a la figura del centrista Kekkonnen, pero ha tenido continuidad con otros Presidentes, aun cuando su adscripción partidaria sea más polarizada. El actual titular, el sr. Koivisto, es de adscripción socialista. 
modelo semipresidencial debería considerar seriamente una cuestión nada desdeñable: la de la configuración política de la elección presidencial y la colateral, pero clave, de su impacto sobre la dinámica del sistema de partidos.

¿Es factible incorporar a los usos chilenos la práctica de despolitizar la elección presidencial?, o, alternativamente, ¿es posible mantener y perpetuar en el tiempo un modelo político que incluya como elemento imprescindible un candidato presidencial sino único apoyado por los partidos que, sumados, agrupen del orden de los dos tercios a tres cuartos del electorado? Si la respuesta fuere positiva los riesgos inherentes al modelo semi-presidencial podrian darse por descartados, $y$ la adquisición de un modelo similar al finés quedaría abierta. En caso contrario las cosas discurrirían de muy otro modo.

Si no fuere posible la despolitización parcial o total de la elección presidencial se plantearía en toda su crudeza el señalado problema de la doble mayoría, y con él los derivados de la coincidencia o no entre ambas, y del eventual conflicto entre ambas mayorías. En consecuencia el riesgo de oscilaciones bruscas en el funcionamiento del sistema de gobierno quedaría abierto y debería ser objeto de debate y consideración a fin de articular los paliativos que pudieren aplicarse.

Adicionalmente debería considerarse el impacto previsible de la dinámica de la elección presidencial sobre la del sistema de partidos. Hay que advertir que en caso de adopción del modelo semipresidencial la cuestión se plantea en términos distintos a los históricos y actuales, toda vez que en el modelo en cuestión la organización de los poderes públicos y la distribución del poder son diferentes a los propios del modelo presidencial. La elección no se plantea igual y el electorado no vota igual para elegir un Parlamento que elige y cesa al Gobierno, que para elegir un Parlamento carente de instrumentos de designación y relevo de aquél. Me parece sugerente invocar al respecto el caso francés, en especial considerando que el paisaje político de 1958 no era estructuralmente distinto del chileno actual. Los redactores del texto galo de 1958, y de las ordenanzas de desarrollo correspondientes, tenían a la vista un sistema de partidos polarizado y fragmentado en el que ningún partido superaba considerablemente el umbral del $25 \%$ del voto, y en el que, en consecuencia, era improbable una mayoría parlamentaria. Al mismo aplicaron el sistema electoral tradicional: el uninominal mayoritario a dos vueltas, que permitía asegurar la perduración del multipartidismo y que desde su introducción había generado una dinámica centrípeta productora de coaliciones generalmente inestables que marginaban a los extremistas. Pues bien, el mismo scrutin d'arrondis- 
sement que durante setenta años había producido coaliciones lábiles y poco disciplinadas de orientación centrista, bajo el impacto de la elección presidencial directa por mayoría absoluta introducida en 1962 ha producido un multipartidismo polarizado, mediando por coaliciones sólidas y disciplinadas, que giran en torno al liderazgo o la oposición al liderazgo presidencial: la lógica dualista de la elección presidencial ha colonizado y sometido a la elección parlamentaria, y ello pese a un tipo de escrutinio no especialmente favorable. El sistema de partidos chileno ¿es inmune a esa contaminación? Si, como me temo, la respuesta fuere negativa el atractivo de la opción semipresidencial menguaría considerablemente.

\section{LA POSIBLE VÍA PARLAMENTARIA}

¿Porqué excluir la opción parlamentaria? En principio una reforma que convirtiera en parlamentaria a la Constitución de la República cuenta con argumentos favorables nada desdeñables. Así la forma parlamentaria está exenta de los riesgos de bloqueo inherentes a la presidencial: en el caso del parlamentarismo cualquier conflicto entre el Ejecutivo y el Parlamento tiene solución constitucional; además es una forma de gobierno compatible con casi cualquier sistema de partidos $y$, en todo caso, lo es con partidos fuertemente cohesionados y disciplinados, hasta el punto que precisamente ese tipo de partidos permiten resolver algunos de los problemas que la imitación europea del modelo británico registró hasta la ll Guerra Mundial; adicionalmente la forma parlamentaria admite y cobija variantes de un espectro lo suficientemente amplio como para satisfacer casi cualquier estructura de necesidades. A diferencia de la forma presidencial, notablemente rígida, la forma parlamentaria es lo suficientemente elástica como para adaptarse a casi cualquier distribución del poder, entre el régimen "de canciller" y sus gobiernos de legislatura y el "parlamentarismo a la francesa", lindante con el régimen de asamblea, no puede decirse que las modalidades disponibles sean escasas. Es más, ni siquiera resulta aceptable el reproche de fragilidad o debilidad de la Jefatura del Estado pues el parlamentarismo monista ha mostrado capacidad para convivir con una Presidencia cualquier cosa menos simbólica.

Una reforma en sentido parlamentario incluso puede adaptarse a la fuerte personalización del Ejecutivo, que la observación muestra no ser ciertamente ni una propiedad exclusiva del sistema presidencial, ni una peculiaridad de la cultura política latinoamericana. 
Pese a que una reforma parlamentaria eludiría el problema del bloqueo institucional no parece que sea una vía que cuente con un apoyo considerable, y no me parece precisamente casual que ninguna democracia latinoamericana haya ensayado con éxito del parlamentarismo. A mi juicio la forma parlamentaria choca con un triple obstáculo: en primer lugar tiene una imagen desfavorable en Chile; en segundo lugar plantea difíciles problemas de adaptación en una cuestión crucial: la elección del Presidente; finalmente choca con los hábitos y la cultura política dominante.

El primer obstáculo es de índole histórica: la mal llamada «república parlamentaria» ${ }^{24}$, no ha dejado un buen recuerdo, ni entre las élites, ni en los partidos, ni entre los líderes de opinión. En consecuencia se ha edificado un estereotipo negativo de carácter en buena medida mítico, que permea la cultura política chilena de cierta hostilidad hacia la forma parlamentaria. Su falta de fundamentación histórica y su debilidad racional no minimizan un ápice una realidad con la que hay que contar: el entorno es hostil hacia el parlamentarismo, al que en la conciencia social se orna de connotaciones negativas. En este sentido la situación chilena se asemeja considerablemente a una imagen invertida de la española en los años de la transición: allá el régimen autoritario, la proclividad falangista por la forma presidencial y el contexto europeo generaron una visión negativa del presidencialismo que condujo a su virtual exclusión como alternativa en los debates constituyentes. La democracia española debía ser parlamentaria, acá las cosas funcionan casi exactamente igual: el prejuicio es tan fuerte que oblitera casi cualquier posibilidad de actuación en el sentido apuntado, superar el prejuicio comporta unos costes de oportunidad insoportables.

Por si el obstáculo señalado fuera escaso la reforma en sentido parlamentario adolece de una debilidad fundamental: sentado que el parlamentarismo debe ser monista ${ }^{25}$ surge la cuestión de la provisión de la Presidencia de la República. La elección directa, al modo irlandés o islandés, debe excluirse, pues resulta inconcebible en el contexto chileno un Presidente de elección popular que no tenga parte en el Poder Ejecutivo, y una reforma parlamentaria que mantuviera la elección directa supondría, en el contexto de referencia, una puerta abierta al des-

24 Mal llamada porque en rigor no se trataba tanto de una forma parlamentaria cuanto del predominio del Parlamento sobre el Ejecutivo. Más que parlamentarismo habría que hablar de "Congressional Gouvernement".

25 Una fórmula de parlamentarismo de doble confianza en el contexto chileno significa deslizarse velis nolis hacia el modelo semi-presidencial. 
lizamiento semipresidencial mediante una interpretación expansiva del Poder Moderador. Resta o bien la elección parlamentaria, o bien un sistema mixto al estilo del previsto por el texto español de 1931 o el italiano aún vigente. Tal vía posibilitaría un Presidente-moderador, pero conduce a una pregunta cuya contestación me parece ociosa: ¿sería no ya popular, sino meramente entendible por un electorado habituado de larga data a la elección directa de los gobernantes, un sistema constitucional en el que no hay otra elección directa que la del Parlamento? ¿Qué aceptación tendría un sistema como el italiano en el que el Presidente y el Gobierno nacen únicamente de la voluntad de los representantes, sin que haya en ningún caso intervención inmediata y directa de los representados?

Porque la cuestión del método de elección presidencial nos lleva a la cuestión de fondo, que no es otra que una cuestión de cultura política: una reforma de las instituciones que conformara a éstas de acuerdo con el modelo parlamentario ¿sería compatible con la cultura política dominante en Chile? Y me temo que la respuesta no sería ciertamente positiva.

Llegamos así a una situación paradójica: salimos del modelo presidencial huyendo del riesgo de bloqueo y nos encontramos con que la alternativa que menos se separa de la cultura política dominante y aparece como más viable exige unas condiciones ecológicas tan estrictas que su satisfacción es más bien difícil en el caso de Chile, que en caso de déficit de aquellas condiciones el sistema de gobierno si bien minimiza no hace desaparecer el riesgo de bloqueo y tiene el inconveniente de estar sujeto al riesgo de oscilaciones brutales. $Y$ que la introducción de la fórmula que permite eludir el riesgo de bloqueo tiene tales costes de oportunidad que su introducción resulta de una gravosidad tal que hace difícilmente viable la operación, y que si la misma llegara a triunfar tendría a corto y medio plazo un horizonte azaroso. No parece sino que sólo nos queda regresar al punto partida: la constitución presidencial.

\section{5. ¿EL PARLAMENTARISMO DE ELECCIÓN DIRECTA?}

El debate institucional ha apuntado en los últimos tiempos una posibilidad que merecería una discusión más detenida: la apuntada por la propuesta Duverger-Charlot de reforma de la Constitución francesa de 1946, adoptada por comisión neerlandesa de reforma de las instituciones a mediados de los sesenta, y finalmente implantada por la re- 
forma israelí de 1994/96: lo que podemos llamar el parlamentarismo de elección directa ${ }^{26}$. La propuesta en cuestión conserva la estructura general de la forma de gobierno parlamentaria: un ejecutivo dualista en el que el Jefe del Estado cumple esencialmente funciones moderadoras y simbólicas, en tanto que el Poder Ejecutivo es ejercido por el Gobierno, la formación periódica de éste a partir del resultado de las elecciones parlamentarias, la regulación de las relaciones GobiernoParlamento por el juego de los principios de confianza y responsabilidad, el mantenimiento de instituto de la disolución, etc., pero introduce cuatro innovaciones estrechamente relacionadas entre sí: en primer lugar el primer ministro deja de ser nombrado por el Jefe del Estado o investido por el Parlamento para pasar a ser electo mediante sufragio universal directo; en segundo lugar la elección de premier y la elección parlamentaria son simultáneas y se verifican en unidad de acto; en tercer lugar el primer ministro electo por el pueblo forma gobierno a la vista del resultado de la elección parlamentaria, gobierno que es responsable ante el Parlamento; cuarto, el Parlamento puede exigir responsabilidad al Gobierno mediante el voto de una moción de censura, a su vez el Primer Ministro puede plantear a la Cámara la cuestión de confianza, pero si la cuestión de confianza es rechazada o la moción de censura aprobada, el Presidente de la República cesa al premier, disuelve el Parlamento y convoca elecciones simultáneas a la presidencia del Gobierno y al Parlamento a fin de que el cuerpo electoral decida.

Una propuesta de este tipo, aun matizada ${ }^{27}$, permitiría alcanzar los objetivos que se pretenden conseguir mediante la propuesta de un modelo semi-presidencial, sin necesidad de incurrir en los inconvenientes propios del mismo, y sin incurrir en la mayor parte de los inconvenientes que hacen poco aconsejable para Chile un modelo estrictamente parlamentario, entre otras razones porque haría desaparecer el obstáculo mayor que a este último se opone: la ausencia de toda elección popular fuera de la de los parlamentarios. No obstante registra inconvenientes propios, de los cuales me parecen relevantes tres: en primer lugar como fórmula novedosa que es no tiene tras sí una larga experiencia de funcionamiento que permita un análisis empírico

26 Duverger sugiere denominarlo sistema semi-parlamentario, pero me parece más gráfica la denominación propuesta.

${ }^{27}$ La ley israelí admite la posibilidad de una moción de censura que no da lugar a disolución y permite la elección parlamentaria del Primer Ministro si se vota por una mayoría cualificada (muy difícil de alcanzar en el contexto hebreo), y permite asimismo un gobierno estrictamente parlamentario durante la etapa final de cada Legislatura. 
de su funcionamiento y que pudiera alumbrar sus posibles vicios más o menos ocultos, como innovación que es arrastra los riesgos que a ésta son inherentes, adicionalmente la aún breve experiencia israelí no es suficientemente ilustrativa, no sólo por esa brevedad, sino también por las especialísimas condiciones de vida del citado Estado; en segundo lugar el funcionamiento del modelo depende en gran medida del sistema electoral a emplear en la elección parlamentaria y del comportamiento de los electores, en principio el modelo se ha pensado para una elección parlamentaria de corte proporcional, $y$ en el caso israelí así sucede, el sistema electoral hebreo tiene un índice de proporcionalidad altísimo ${ }^{28}$, y no se ha considerado suficientemente supuesto distinto, de otro lado la simultaneidad de elecciones está pensada para facilitar la contaminación de la elección parlamentaria por la del Primer Ministro, pero hay que considerar la eventualidad de que se produzca más bien un efecto diverso: como la elección parlamentaria no implica la del gobierno, que se independiza, los elementos de decisión estratégica en la configuración del voto en la elección parlamentaria pueden desvanecerse, parafraseando el dicho electoral francés, en la urna parlamentaria se puede pasar de votar por utilidad a votar por simpatía ${ }^{29}$; en tercer lugar el sistema requiere de una fórmula alternativa para la elección presidencial, que difícilmente puede ser directa (so pena de correr el riesgo de creación de un "consulado") y que se aviene mal con una elección parlamentaria, al menos en el caso de que el Parlamento sea unicameral, del mismo modo que requiere de una exquisita precisión para determinar el alcance de la intervención presidencial en las crisis: ¿debe el Jefe del Estado tener algún margen de actuación discreccional o no?, pues la dinámica del modelo será significativamente distinta $-y$ el estatuto presidencial también- según sea la respuesta. Acaso sean demasiadas incertidumbres.

En definitiva, el mantenimiento del modelo presidencial con partidos al estilo europeo hace al sistema institucional altamente vulnerable al riesgo de bloqueo institucional en caso de divergencia de las mayorías parlamentaria $y$ presidencial en un contexto de elevada polarización política. La experiencia de 1973 señala que los costes co-

${ }^{28}$ En buen medida porque la Knesset se elige en régimen de circunscripción nacional única. Es interesante recordar que en el primer caso en que el modelo se tradujo en una propuesta completa y detallada, el holandés, la elección de la Segunda Cámara de los Estados Generales también se verifica con tal régimen.

${ }^{29}$ En la única elección israeli, la de 1996, hay indicios de escisión de voto basados en la reserva del voto estratégico para la elección del premier y en la decisión de voto por simpatía en la elección parlamentaria. 
rrespondientes pueden ser elevadísimos. No obstante la alternativa que minimiza dicho riesgo, la parlamentaria, es de viabilidad problemática en el contexto chileno y la más factible alternativa semi-presidencial presenta riesgos propios que incluyen la posibilidad, ciertamente lejana pero factible, del bloqueo que se pretende evitar. $Y$ la opción por el parlamentarismo de elección directa tiene fuertes incertidumbres, por hallarse poco menos que en fase experimental. La decisión, porque de una decisión política se trata, no es fácil. Mas la decisión misma no es una cuestión técnica o científica y se halla más allá del campo de acción propio del constitucionalista, pues, como gustaba advertir Weber, no es posible optar entre compromisos fundamentales con los instrumentos de la ciencia. 